\title{
Frontal Mucocele Presenting with Subcutaneous Cystic Swelling: An Unusual Case Report
}

\author{
${ }^{1}$ Bhushan Chauhan, ${ }^{2}$ Manish Gupta
}

\begin{abstract}
Paranasal sinus mucocele is slowly expanding cystic lesions leading to sinus expansion, bony erosion and extension into the orbit, cranial cavity or into subcutaneous tissue. Mucoceles most commonly involve the frontal and ethmoidal sinuses. We describe a frontal mucocele presenting with forehead subcutaneous cystic mass which was successfully managed by endoscopic sinus surgery and by external approach (frontal trephination).
\end{abstract}

Keywords: Endoscopic sinus surgery, Frontal mucocele, Subcutaneous cystic swelling.

How to cite this article: Chauhan B, Gupta M. Frontal Mucocele Presenting with Subcutaneous Cystic Swelling: An Unusual Case Report. Clin Rhinol An Int J 2015;8(3):130-132.

\section{Source of support: Nil}

\section{Conflict of interest: None}

\section{INTRODUCTION}

A mucocele is chronic, benign, cystic swelling of paranasal sinuses which is having sterile mucoid secretions and is lined by pseudostratified epithelial lining. ${ }^{1}$

It usually develops after chronic obstruction of the ostia of paranasal sinuses by chronic sinusitis, polyps and bony tumor or rarely after surgery. Mucoceles most commonly involve the frontal and ethmoid sinuses. ${ }^{2}$

Due to continued secretions and accumulation of mucous in the mucocele, the pressure in the mucocele increases, which causes pressure necrosis of the bone of sinus. This results in expansion of mucocele in the path of least resistance. This expansion mostly occurs inside the orbit, adjacent sinuses, nasal cavity or through the skin into the subcutaneous tissue.

The authors report a case of frontal mucocele presenting with subcutaneous cystic mass present above medial canthus of left eye by eroding the anterior wall of frontal sinus which was successfully managed by

\footnotetext{
${ }^{1}$ Assistant Professor, ${ }^{2}$ Associate Professor

1,2Department of ENT, Gian Sagar Medical College and Hospital, Patiala, Punjab, India
}

Corresponding Author: Bhushan Chauhan, Assistant Professor, Department of ENT, Gian Sagar Medical College and Hospital, Patiala, Punjab, India, Phone: 01722695281 e-mail: bhushan.chauhan11@yahoo.com combined endoscopic and external approach (frontal trephination) with no recurrence.

\section{CASE REPORT}

A 45-year-old male presented with a 1 year history of swelling over medial canthus of left eye. The swelling was gradual in onset and was progressive since then. There was no history of trauma, headache, blurring of vision, diplopia or epiphora; however, history of persistant mucoid rhinorrhea bilaterally was present. He gave a history of nasal operation twice, first 30 years and second 12 years back for apparent chronic sinusitis via endonasal route. Details of earlier operation and investigations were not available.

On examination, patient had $3 \times 2 \mathrm{~cm}$ swelling over medial canthus of left eye not pushing the left globe (Fig. 1). The swelling was normal temperature, nontender, non pulsatile, nonfluctuant and free from overlying skin. There was no ulceration or discharging sinus. Eye examination revealed no proptosis and there was no loss of vision. Movements of eye ball and fundus examination was normal.

Diagnostic nasal endoscopy performed under local anesthesia revealed S-shaped nasal septum with upper part deviated toward right side and lower part toward left side with bony spur touching the middle turbinate. Multiple polyps were present in the right nasal cavity. Hematological and biochemical parameters were normal.

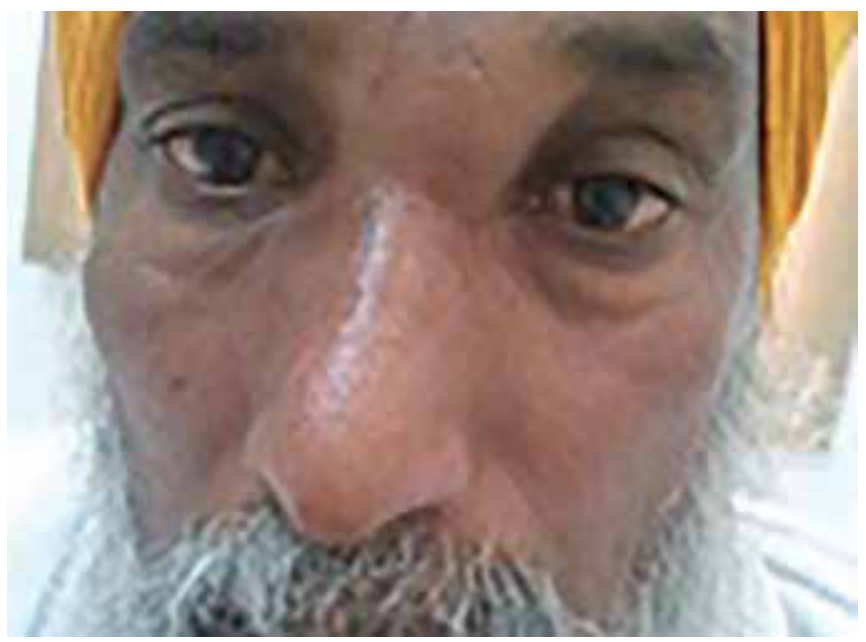

Fig. 1: Preoperative clinical photograph showing swelling over medial canthus of left eye 


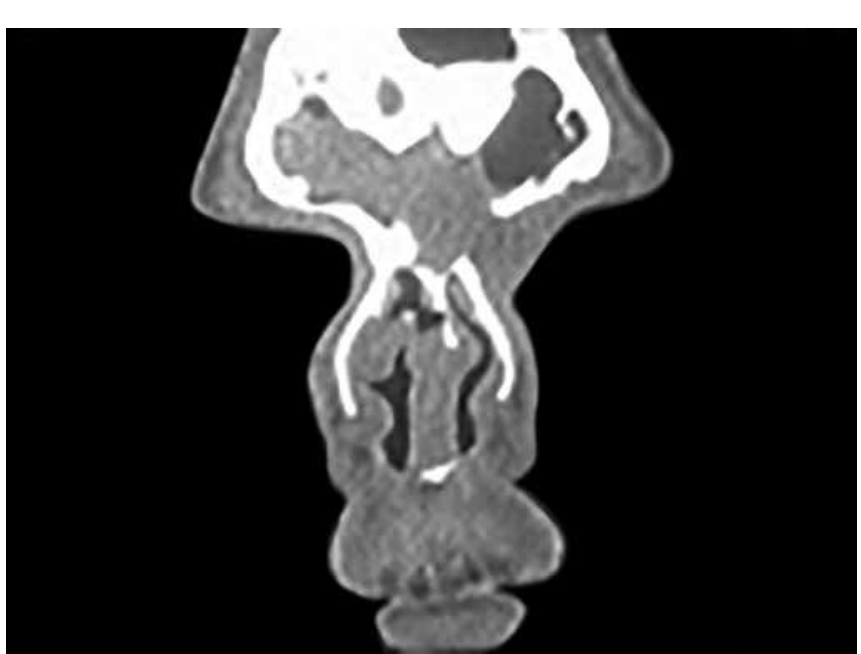

Fig. 2: Coronal section computed tomogram showing soft-tissue density in frontal sinus and subcutaneous tissue

Computered tomography (CT) of nose and paranasal sinuses showed well defined soft-tissue density in ethmoid sinuses $(R>L)$ with erosion of anterior walls of frontal sinuses and extension of soft-tissue into subcutaneous tissue of center of forehead (Figs 2 and 3). Nasal septum was S-shaped.

Based on the clinical and radiological findings, the most likely diagnosis was a frontal mucocele with extension into subcutaneous tissue of center of forehead.

After performing conventional septoplasty with bilateral functional endoscopic sinus surgery (FESS). It was found that mucocele was not accessible endoscopically thus left external frontoethmoidectomy was planned intraoperatively. A left sided Lynch Howarth incision, about $4 \mathrm{~cm}$ in length was made beneath the medial end of the left eye brow, cutting through skin, subcutaneous tissue and periosteum (frontal trephination approach). A soft swelling corresponding to mucocele was encountered with left frontal anterior wall defect. The sac of frontal mucocele was exposed and blunt dissection was done all around. After removing the thick soft-tissue wall of mucocele, left frontal sinus was opened and found to be normal. Then interfrontal sinus septum was found to be eroded and through it right frontal sinus was entered and mucocele of right frontal sinus was excised completely. Both right and left frontal sinuses were opened in their respective meatuses endoscopically. The mucocele was found to contain thick discolored fluid which was sent for culture. The culture sensitivity test for the aspirated mucus showed no growth after 48 hours. There were no complications perioperatively. Postoperatively, there was complete resolution of swelling. The patient was discharged on the second postoperative day following pack removal. The external stitches were removed on 7 th postoperative day. The 6 months follow-up endoscopy showed wide draining frontal recess with no recurrence.

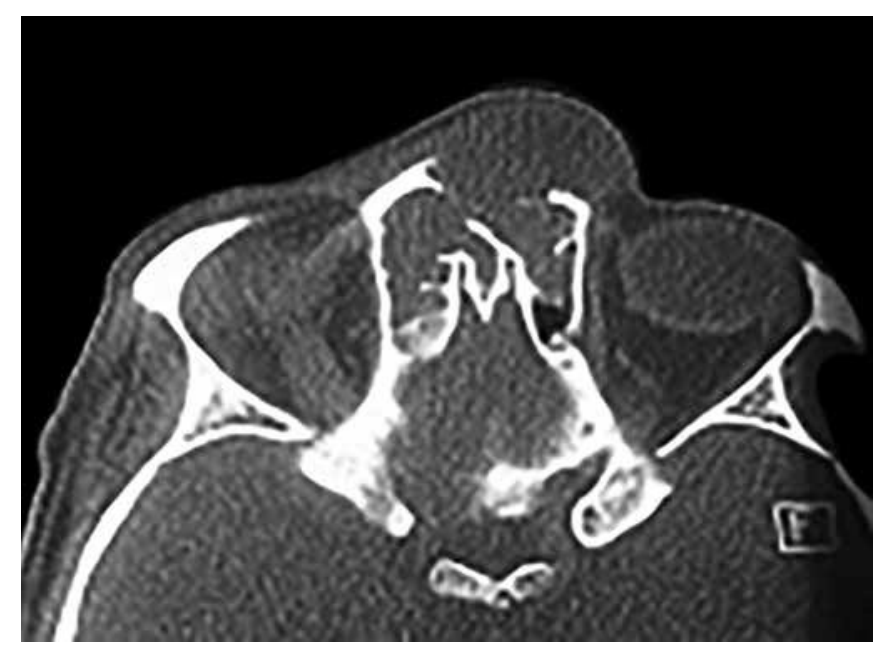

Fig. 3: Axial section computed tomogram showing soft-tissue density in subcutaneous tissue

\section{DISCUSSION}

Mucoceles are the mucus secreting, benign, cystic lesions of paranasal sinuses and capable of expansion due to dynamic process of bone resorption and new bone formation. ${ }^{3}$ Mucocele can develop either due to obstruction of the duct of mucus gland which is located in lining of paranasal sinus or due to obstruction of sinus ostium, so histologically mucocele may be primary or secondary. Primary mucocele are mucous retention cyst while secondary mucocele also called true mucocele are lined by pseudostratified columnar epithelium and they are formed due to obstruction of sinus ostium. ${ }^{4}$

Mucocele is diagnosed on the basis of history, physical examination and radiological findings. Computed tomography is a imaging modality of choice for diagnosis of mucocele. It clearly shows expanded, airless, mucoid density filled, non-enhancing sinus mass, ${ }^{5}$ but magnetic resonance imaging (MRI) is useful in infected cases to find out the exact intracranial or intraorbital extension.

The walls of involved sinus gradually become thinned and eroded. Frontal sinus mucocele tends to erode posterior wall of sinus because of its thinness. However, in the our case it was the anterior wall of frontal sinus which got eroded and frontal mucocele presented with subcutaneous cystic swelling above medial canthus of left eye.

Mucoceles most commonly involve the frontal and ethmoid sinuses. ${ }^{2}$ The symptoms of mucocele depends on its site and extent of bony erosion. Complications can arise due to infection or expansion of mucocele in its surrounding structures. They may extend into the orbit, adjacent sinuses, nasal cavity, intracranial or through the skin. ${ }^{6}$ Very rarely frontal mucocele can present as subcutaneous cystic swelling which was present in our case. 
Mucocele sometimes get infected (mucopyocele), and may present with cellulitis in soft-tissuses, osteomyelitis and septicemia. Mucoceles arising from the frontal sinus, when involve the orbit results in variety of clinical signs such as decreased visual acuity, visual field abnormalities, proptosis, ptosis, periorbital swelling, displacement of the globe and restricted ocular movements. ${ }^{7,8}$ Proptosis is usually the main complaint and oculomotor nerve palsy is rare. ${ }^{9}$ Diplopia occurs when globe is displaced in downward and outward direction. ${ }^{10}$ When mucocele involve the intracranial structures it may lead to meningitis, meningoencephalitis, brain abscess or cerebrospinal fluid (CSF) fistulas. ${ }^{11}$

The goals of surgery are eradication of the mucocele with minimal morbidity and prevention of recurrences. The choice of surgical treatment for mucocele of paranasal sinuses depends upon its size, site and extent of mucocele. $^{12}$

Surgical treatment range from functional endoscopic sinus surgery to craniotomy and craniofacial exposure with or without obliteration of the sinus. ${ }^{13}$ Some surgeons prefer the combined endoscopic and craniotomy approach for the treatment of frontal mucoceles. ${ }^{14}$ Some suggest that even in patients with intracranial extension, the intranasal approach is better as it is less invasive and the lesion can be completely removed without the need of craniotomy. ${ }^{15}$

Transcranial approach is an extended procedure which involves external incision, periosteal elevation and fracturing of sinus floor in creation of flaps which has large morbidity because stripping of mucocele leads to dural injury and CSF leaks. ${ }^{16}$

The combined approach is used in more severe cases where the anatomy, extent of disease, or previous surgery restricts endoscopic visualization and access to the frontal sinus. ${ }^{17}$ In our case the endoscopic approach along with external approach (Lynch-Howarth) was used for removal of frontal mucocele present as subcutaneous cystic swelling and it was successfully removed with no recurrence. Thus a complex or revision cases may necessitate a combined endoscopic and external drainage procedure in order to prevent recurrence.

\section{REFERENCES}

1. Stiernberg CM, Bailey BI, Calhoun KH, Quinn FB. Management of invasive frontoethmoidal sinus mucoceles. Arch Otolaryngol Head Neck Surg 1986 Oct;112(10):1060-1063.

2. Ormerod LD, Weber AL, Rauch SD, Feldon SE. Ophthalmic manifestations of maxillary sinus mucoceles. Ophthalmology 1987 Aug;94(8):1013-1019.

3. Gavioli C, Grasso DL, Carinci F, Amoroso C, Pastore A. Mucoceles of the frontal sinus: clinical and therapeutical considerations. Minerva Stomatol 2002 Sept;51(9):385-390.

4. Marks SC, Latoni JD, Mathog RH. Mucoceles of the maxillary sinus. Otolaryngol Head Neck Surg 1997;117:18-21.

5. Rao VM, Sharma D, Madan A. Imaging of frontal sinus disease: concepts, interpretation, and technology. Otolaryngol Clin North Am 2001 Feb;34(1):23-39.

6. Suri A, Mahapatra AK, Gaikwad S, Sarkar C. Giant mucoceles of the frontal sinus: a series and review. J Clin Neurosci 2004 Feb;11(2):214-218.

7. Hayasaka S, Shibasaki H, Sekimoto M, Setogawa T, Wakutani T.Ophthalmic complications in patients with paranasal sinus mucopyoceles. Ophthalmologica 1991;203(2):57-63.

8. Leventer DB, Linberg JV, Ellis. Frontoethmoidal mucoceles causing bilateral chorioretinal folds. Arch Ophthalmol 2001 Jan;119(6):922-923.

9. Lin CJ, $\mathrm{Kao} \mathrm{CH}$, Kang BH, Wang HW. Frontal sinus mucocele presenting as oculomotor nerve palsy. Otolaryngol Head Neck Surg 2002 May;126(5):588-590.

10. Khong JJ, Malhotra R, Wormald PJ, Selva D. Endoscopic sinus surgery for paranasal sinus mucocele with orbital involvement. Eye 2004 Sept;18(9):877-881.

11. Galie M, Mandrioli S, Tieghi R, Clauser L. Giant mucocele of the frontal sinus. J Craniofac Surg 2005 Sept;16(5):933-935.

12. Koike Y, Tokoro K, Chiba Y, Suzuki SI, Murai M, Ito H. Intracranial extension of paranasal sinus mucocele: two case reports. Surg Neurol 1996 Jan;45(1):44-48.

13. Weitzel EK, Hollier LH, Calzada G, Manolidis S. Single stage management of complex fronto-orbital mucocele. J Craniofac Surg 2002 Nov;13(6):739-745.

14. Natvig K, Larsen TE. Mucocele of the paranasal sinuses. A retrospective clinical and histological study. J Laryngol Otol 1978 Dec;92(12):1075-1082.

15. Delfini R, Misson P, Lannetti G, Ciappetta P, Contore G. Mucoceles of the paranasal sinuses with intracranial and intraorbital extension: report of 28 cases. Neurosurgery 1993 Jun;32(6):901-906; discussion 906.

16. Har-EL G. Endoscopic management of 108 sinus mucoceles. Laryngoscope 2001 Dec;111(12):2131-2134.

17. James E, Dutta A, Swami H, Ramakrishnan R. Frontal mucocele causing unilateral proptosis. MJAFI 2009 Jan;65(1):73-74. 